\section{The authors respond to "The 2017 Canadian opioid guideline: already time for an overhaul"}

We were disappointed to receive the letter by Kahan and colleagues, ${ }^{1}$ which suggests the authors did not read our guideline carefully.

We share their concerns regarding inappropriate opioid tapering. We have highlighted this concern as it relates to overly aggressive adoption of the US Centers for Disease Control and Prevention Guideline for Prescribing Opioids for Chronic Noncancer Pain. ${ }^{2,3}$ The 2017 Canadian guideline for opioid therapy and chronic noncancer pain ${ }^{4}$ explicitly discourages inappropriate opioid tapering, a position that was informed by our guideline's values and preferences statement, which reads, in part:

"... our focus group interviews revealed that some patients using long term opioid therapy for chronic non-cancer pain were concerned about adverse consequences of opioid withdrawal that may result from efforts to wean or discontinue their opioid use. For those using high doses of opioids in whom weaning is undertaken, we continue to place a high value on societal considerations of minimizing the risk of rare serious adverse events, but we also place a high value on avoiding severe suffering, increased pain, and functional limitation that may accompany opioid reduction. We also place a high value on patient autonomy under these circumstances." ${ }^{5}$

The 2017 Canadian guideline's Recommendation 9 is that patients using high doses of opioids ( $\geq 90 \mathrm{mg}$ morphine equivalents dose/day) should try to decrease their dose. ${ }^{4}$ There are risks associated with this, including opioid withdrawal. Moreover, as the authors of the letter note, the evidence supporting benefits of reducing opioid dose - decreased risk of unintentional overdose, and improved function - comes from low-quality observational studies. It is thus reasonable for one patient, informed by their physician of the benefits and risks and the associated uncertainty, to choose to try lowering their dose. Another might choose to leave well enough alone. Recognizing this as a decision that is sensitive to values and preferences, the guideline made a weak recommendation for reducing opioid dose.

A weak recommendation indicates that most informed patients would choose the suggested course of action, but an appreciable minority would not. With weak recommendations, clinicians should recognize that different choices will be appropriate for individual patients, and should assist patients to arrive at a decision consistent with their values and preferences. Weak recommendations should not be used as a basis for standards of practice, other than to mandate shared decision-making.

Further, the explanatory information associated with Recommendation 9 reads as follows: "Some patients may have a substantial increase in pain or decrease in function that persists for more than one month after a small dose reduction; tapering may be paused and potentially abandoned in such patients." 4

Kahan and colleagues ${ }^{1}$ also note that our guideline does not address treatment of opioid use disorder. We highlighted this in the Scope section of the guideline. ${ }^{4}$ Although this is an important issue, it was not within our mandate. The same is true of acute pain, pain resulting from cancer, or pain at the end of life.

We reiterate our view that, if followed, the 2017 Canadian guideline will promote evidence-based prescribing of opioids for chronic noncancer pain.

\section{Jason W. Busse DC PhD}

Associate professor, Michael G. DeGroote Institute for Pain Research and Care, Departments of Anesthesia, and Health
Research Methods, Evidence and Impact, McMaster University, Hamilton, Ont.

\section{David Juurlink MD PhD}

Professor, Departments of Medicine and

Paediatrics, University of Toronto,

Toronto, Ont.

\section{Norman Buckley MD}

Professor and chair, Michael G. DeGroote Institute for Pain Research and Care, Department of Anesthesia, Hamilton, Ont.

\section{Gordon H. Guyatt MD MSc}

Distinguished professor, Department of Health Research Methods, Evidence and Impact, Michael G. DeGroote Institute for Pain Research and Care, McMaster University, Hamilton, Ont.

- Cite as: CMAJ 2018 March 12;190:E301. doi: $10.1503 / \mathrm{cmaj} .68675$

\section{References}

1. Kahan M, Dubin R, Clarke H. The 2017 Canadian opioid guideline: already time for an overhaul [letter]. CMAJ 2018 March 12;190:E300. doi: 10.1503/cmaj .68662

2. Busse JW, Juurlink D, Guyatt GH. Addressing the limitations of the CDC guideline for prescribing opioids for chronic noncancer pain. CMAJ 2016; 188:1210-1.

3. Busse JW, Juurlink D, Guyatt GH. Response to "Clarification from the College of Physicians and Surgeons of BC on commentary about limitations of the CDC guideline for prescribing opioids." CMAJ 2017;189:E509.

4. Busse JW, Craigie S, Juurlink DN, et al. Guideline for opioid therapy and chronic noncancer pain. CMAJ 2017;189:E659-66.

5. 2017 Canadian Guideline for Opioids for Chronic Non-cancer Pain Values \& Preferences statement. Hamilton (ON): McMaster University; 2017. Available: http://nationalpaincentre.mcmaster.ca/ documents/Values and Preferences Statement English.pdf (accessed 2017 Dec 1).

Competing interests: All authors are members of the Steering Committee for the Canadian Guideline for Opioid Therapy and Chronic Noncancer Pain. David Juurlink was a member of the Stakeholder Review Group for the US Centers for Disease Control and Prevention Guideline for Prescribing Opioids for Chronic Pain. No other competing interests were declared. 